\section{Wittgenstein and reality}

SIR - It is quite understandable that a gung-ho positivist, who unquestioningly accepts what he sees as reality, is annoyed by someone such as Wittgenstein and wants to rubbish him. However, the grounds selected by J. R. Smythies (Nature 350, 9; 1991) who says that Wittgenstein was talking 'schizophrenese' - a form of speech disorder characterized by the fact that the meaning of a schizophrenesiac proposition is not wholly contained within it - will not do.

Of course, it would be easy to reject anything we do not understand as a distorted proposition or a non-proposition, and this is just what Wittgenstein, in common with the logical positivists, tried to do in the Tractatus. However, as Wittgenstein's later work (especially the Philosophical Investigations) shows, no proposition or set of propositions wholly contains their meaning. An understanding of the meaning of a proposition always depends upon other, external, factors. We understand one another - for example, I understand Smythies and Smythies understands his patients - because we share a common set of assumptions with which to interpret our communications. Lacking such a mutual basis we must seek it out and fail to find it before we can dismiss propositions under such a rubric as 'schizophrenese'.

It might indeed be thought that to reject an investigation of the meaning of scientific statements (which is the business of philosophy), while confidently accepting their validity, is more truly a sign of a schizophrenic (shattered) view of reality.

R. J. BIRD

Department of Applied Social Science, Newcastle upon Tyne Polytechnic, Newcastle upon Tyne, NE1 8ST, UK

SIR - J. R. Smythies' explanation and dismissal of Wittgenstein's philosophy is that he was a schizophrenic writing poetry in German. That necessarily implies an admirably humble confession of a difficulty in grasping some of the illuminating aphorisms, yet it is as helpful in evaluating Wittgenstein's thought as the comment on a recent esoteric French philosopher, that he died of AIDS.

Turning the tables on Smythies, one can note that his letter reveals his quasi-religious paradigmatic belief that the neurosciences are those "from which ... our only true understanding of the mind can come". Wittgenstein saw philosophy as therapy for such misplaced confidences. Perhaps he would have thought of Goethe, Shakespeare, Cervantes, Kafka et al. This is no denial of the validity and achievements of scientific enquiry. There is, however, a warning that much thought, as is most especially true for example of mathematical creations, may depend on axioms utterly obvious but only to whole generations influenced by Zeitgeister. Extrapolating from what is successful for some issues to everything is at least questionable. Is it too germanic to note that mysteries about Being remain, or to wonder whether there is something wrong in the basic formulations we use in trying to grasp how conscious experience could evolve from matter as we have to conceive it?

Wittgenstein was undoubtedly a very disturbed and distraught person but in the light of psychiatry's own difficulties with the word schizophrenia, is much achieved by a diagnosis in this context? I must, of course, confess my own insecure and heretical position. It stresses the personal politics involved in indicating the similarities or differences between us and those called schizophrenic. That is done in part to emphasize either our ability to empathize or their strangeness. Much that many of them say is to some of us instructive as they are to a significant degree defined by their apparent emotional need to stand painfully outside complicity with the common sense of the period. Perhaps it is appropriate here to quote Karl Jaspers (1946), who went a long way to define who are schizophrenics. They are those whom among other things, he said, we cannot understand (Verstehen) humanly so must explain (Erklaren) scientifically. Nevertheless, he added (much nearer to my views), "extreme psychotic states offer a parable - patients see into depths which do not belong so much to their illness as to themselves as individuals with their own historical truth ... in psychotic reality we find an abundance of content representing fundamental problems of philosophy.... The philosopher in us cannot but be fascinated by this extraordinary reality and feel its challenge."

\section{University of Sheffield,}

Department of Psychiatry,

Royal Hallamshire Hospital,

Glossop Road,

Sheffield S10 2JF, UK

aspers, K. Aligemeine Psychopathologie (Springer, Heidelberg, 1946).

\section{Cancer-EMF connection}

SIR - Nature has recently $(349,554 ; 1991)$ discussed the cancer-electromagnetic field connection. When two phenomena correlate, but no obvious direct linkage exists, it is worthwhile asking whether an indirect linkage may exist.

Cancer is well know to correlate with action of highly reactive chemicals on tissue. The presence of certain types of electrical systems can result in the production of highly reactive chemicals. Thus, for example, highvoltage transmission lines can be expected to produce ionization of air as a result of discharges, and production of low levels of materials such as ozone and nitrogen oxides. Similarly, if electric hair-driers have motors with brushes, the sparks at the brushes could have similar results, while the high voltages used in television sets for the cathode-ray tubes could potentially do the same.

The reactive gases would have a relatively high local concentration near the device that produces them and so potentially account for the reported correlations. Could there be a correlation between the use of heavier wiring and large motors (because of starting currents)? This could again help produce the unexpected correlation.

University of Arizona,

Steward Observatory,

Tucson, Arizona 85721, USA

\section{Health risks}

SIR - David Lindley (Nature 346, 507; 1991) makes the valid suggestion that public fears about health risks could be mitigated if scientists presented statistical arguments more precisely so that the public understood them better. In passing, however, he appears to give credence to the popular misconception that nuclear power is 'safe' compared with not wearing a motorcycle helmet or seat belt. But in terms of unit risk of death, the converse is true. Motorcycle helmets and seat belts have not been proved to reduce individual risk of death (and probably do not, see J. G. U. Adams Ergonomics 31, $407-428 ; 1988$ ), whereas nuclear power is known to have killed.

This example illustrates the important point that statistical arguments are futile when addressing public health fears because the objective statistical information is simply not available in matters of national policy. Where, for example is the evidence that crash helmets and seat belts 'save lives'? These unproven devices are promoted as beneficial (in the absence of evidence) and thus deflect public attention from the fact that a transport policy that encourages private road transport (responsible for 5,000 accident fatalities a year in the United Kingdom) is inherently dangerous. In similar vein, energy efficiency, although cheaper and inherently safer than nuclear power, is not national policy and thus not promoted. People certainly often appear to be 'pennywise and pound-foolish' in their personal risk perception. But underlying this actuarial schizophrenia is the uncomfortable reality that public policy often dictates the risks the public are forced to take. The public, of course, orders its fears accordingly.

SiMON P. WOLFF

Department of Clinical Pharmacology,

UCMSM,

University College London,

5 University Street,

(The Rayne Institute),

London WC1E 6JJ, UK 